\title{
ATTITUDES TOWARD BIOSTATISTICS AMONG POST-GRADUATE MEDICAL STUDENTS IN KISHANGANJ, BIHAR
}

Laxman Kumar¹, Kashif Shahnawaz², Sanjay Kr. Choudhary³,Gautam Sarker ${ }^{4}$, Sanjiv Kumar Barman ${ }^{5}$, jitendra Bahadur Singh6.

\section{HOW TO CITE THIS ARTICLE:}

Laxman Kumar, Kashif Shahnawaz, Sanjay Kr. Choudhary, Gautam Sarker, Sanjiv Kumar Barman, jitendra Bahadur Singh. "Attitudes toward Biostatistics among Post-Graduate Medical Students in Kishanganj, Bihar". Journal of Evolution of Medical and Dental Sciences 2014; Vol. 3, Issue 03, January 20; Page: 758-761, DOI:10.14260/jemds/2014/1898

\begin{abstract}
Background: Biostatistics is a basic and vital tool for medical as well as allied science research. In medical education, biostatistics is taught at undergraduate level without emphasis on its practical aspects and applications. Biostatistics is perceived as important elements of EBM (Evidence Based Medicine). AIMS: Study was done to assess attitude of post-graduate medical students of various disciplines towards biostatistics and also to suggest effective measures to improve understanding of biostatistics. Materials \& Methods: The study was a cross-sectional study, performed in M.G.M.M.C \& L.S.K Hospital, Kishanganj, from Oct.-2013 to Nov.-2013. A total of 257 post-graduate medical students of various disciplines were selected. They were provided printed structured questionnaire containing questions addressing perceptions regarding biostatistics in general, statistical knowledge and training, the role of biostatistics in Evidence Based Medicine (EBM) \& clinical research. Statistical Analysis: This was done in percentage/ proportion, chi-square test. RESULTS: Out of 346 eligible participants, 257 responded to the survey. 231 (89.88\%) believed that biostatistics is important for their career $(\mathrm{P}<0.001) .182(70.81 \%)$ believed that biostatistics is difficult to understand, 187 (72.76\%) had inadequate knowledge as per present need. Conclusion: Post-graduate medical students have low perceived knowledge of biostatistical concepts. Integrated approaches that demonstrate how biostatistics can effect patient care decisions may be more effective. Such approaches would promote biostatistics as a key element of clinical decision.
\end{abstract}

KEY-WORDS: Biostatistics, Post-graduate Students, attitudes.

INTRODUCTION: Biostatistics or Medical statistics is the study of statistics in relation to biological science (such as biological, social and environmental factors) ${ }^{1}$. In medical education, biostatistics is taught at undergraduate level without emphasis on its practical aspects and applications. An improved understanding of biostatistics is necessary for clinicians. Actually, this branch of statistics collects the mathematical factors and data related to health, preventive medicine and disease ${ }^{2}$.This need is clearly recognized by physicians, and even experienced researchers with statistical training report discomfort with biostatistical concepts. Biostatistics is perceived as important elements of EBM (Evidence Based Medicine). At present, due to lack of proper knowledge of biostatistics among Medical Officers (MO's), reporting under IDSP by them is inadequate. Even statistical works in the thesis of post-graduate medical students are not proper.

\section{OBJECTIVES:}

(i) To assess attitude of post-graduate medical students of various disciplines towards biostatistics. 
(ii) Factors responsible for inadequate knowledge of biostatics among PG Medical Students.

(iii)To suggest effective measures to improve understanding of biostatistics.

MATERIALS AND METHODS: This study was a cross-sectional study, performed in M.G.M. Medical College \& L.S.K Hospital, Kishanganj, after obtaining Institutional Ethics Committee approval and consent. Study period was from October-2013 to November-2013. A pre-designed, pretested study schedule in the form of printed structured Questionnaire was used to collect data. Both open and close ended questions were kept in the schedule. Privacy and anonymity of the individuals were maintained. Prior consent was also taken to be included in the study. Those who accepted were included and those who denied were excluded. Confidentiality and ethical issues were also taken into consideration. Sample Size: A total of 257 post-graduate medical students of various disciplines of M.G.M. Medical College \& L.S.K. Hospital, Kishanganj, were selected during study period. They were provided printed structured questionnaire, containing questions addressing perceptions regarding biostatistics in general, statistical knowledge and training, the role of biostatistics in Evidence Based Medicine (EBM) \& clinical research. Demographic data of participants were also collected like sex, disciplines, session, institutions from where they got their medical graduation.

Statistical Analysis: This was done in percentage/ proportion, Chi-square test. Data were primarily analyzed descriptively \& then by EPI Info Software \& online statistical software (http://www.physics.csbsju.edu/stats/). The observations in this study among students were then compiled and results were analyzed.

RESULTS: Out of 346 eligible participants, 257 (74.27\%) responded to the survey, i.e. 188 males and 69 females. 231 (89.88\%) believed that biostatistics is important for their career $(\mathrm{P}<0.001)$, [Fig-1]. $182(70.81 \%)$ believed that biostatistics is difficult to understand $(\mathrm{P}<0.001)$, [Fig-2]. 187 (72.76\%) had inadequate knowledge as per present need $(\mathrm{P}<0.001)$ [Fig-3]. Out of that 187 students, 98 $(52.40 \%)$ believed that there are no faculties of biostatistics in their medical college $(\mathrm{P}<0.001), 72$ $(38.50 \%)$ believed that faculties of community medicine were not interested to teach biostatistics, $17(9.09 \%)$ believed that they were not interested in biostatistics, [Fig-3]. 70 (27.23\%) students believed that they could design their own research project with confidence $(\mathrm{P}<0.001)$. [Fig-4]. 26 $(10.12 \%)$ students believed that they could conduct their own statistical analysis with confidence $(\mathrm{P}<0.001)$. [Fig-5]. 212 (82.49\%) believed that biostatistics is an important part of EBM $(\mathrm{P}<0.001)$. $198(77.04 \%)$ believed that EBM is important for clinical medicine $(\mathrm{P}<0.001)$.

CONCLUSION: Post-graduate medical students have low-perceived knowledge of bio-statistical concepts despite a clear recognition of the importance of these issues. One of the major barriers is the lesser importance of biostatistics relative to other medical subjects, i.e. important but next to medical disciplines. Biostatistics is an important element of EBM; suggest that EBM may represent an ideal vehicle for improved teaching of biostatistics. Integrated approaches that demonstrate how biostatistics can effect patient care decisions may be more effective. Such approaches would promote biostatistics as a key element of clinical decision.

\section{REFERENCES:}

1. Community Medicine with Recent Advances, by AH Suryakantha, $3^{\text {rd }}$ edition, Page no-653. 


\section{ORIGINAL ARTICLE}

2. Text book of Preventive and Social Medicine, by MC Gupta \& BK Mahajan, $3^{\text {rd }}$ edition, Page no371.

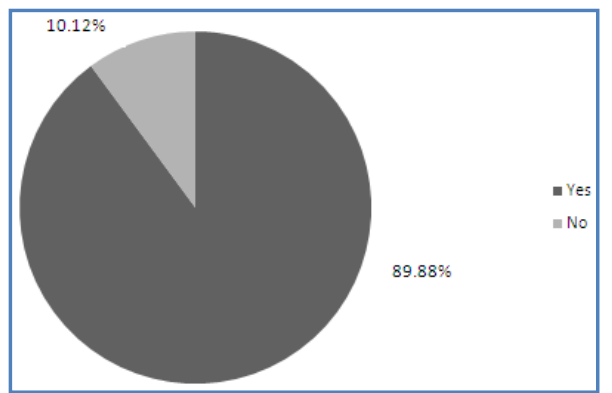

Fig. 1: Importance of Biostatistics

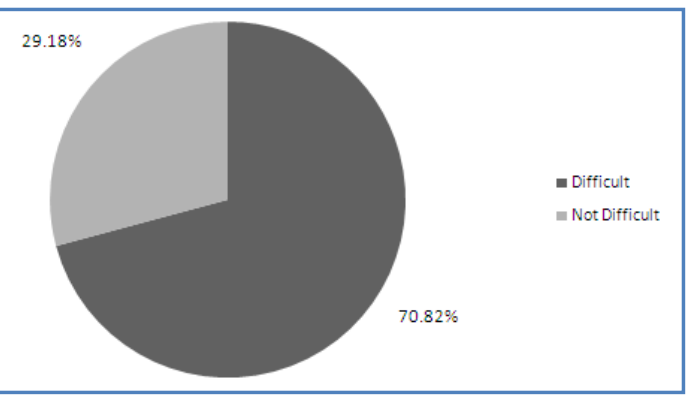

Fig. 2: Understanding Biostatistics

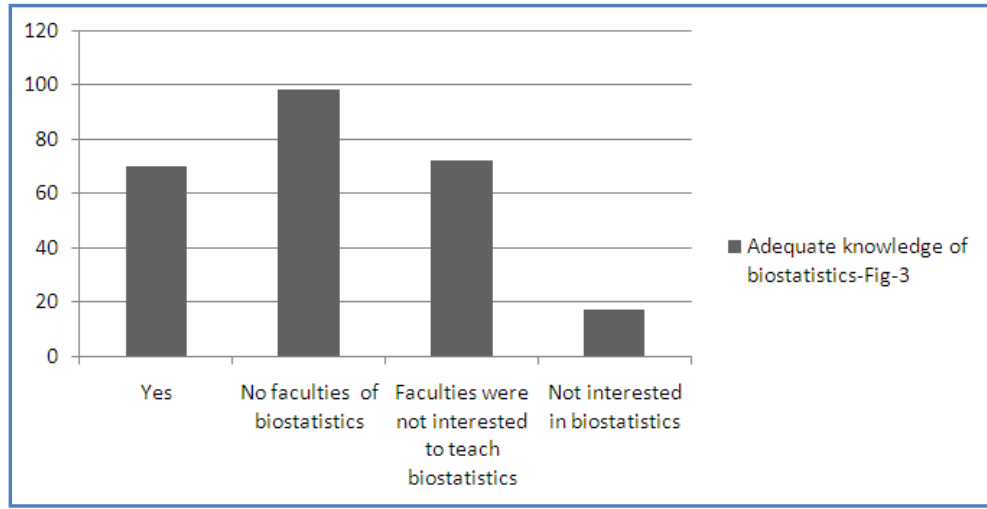

Fig. 3: Adequate knowledge of Biostatistics

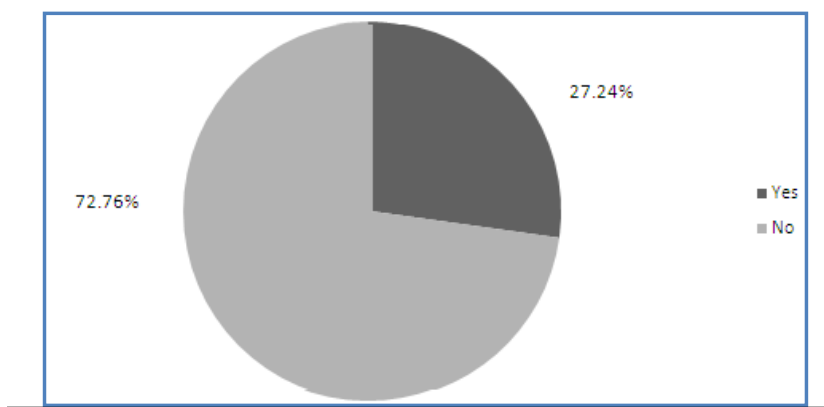

Fig. 4: Design their own research project

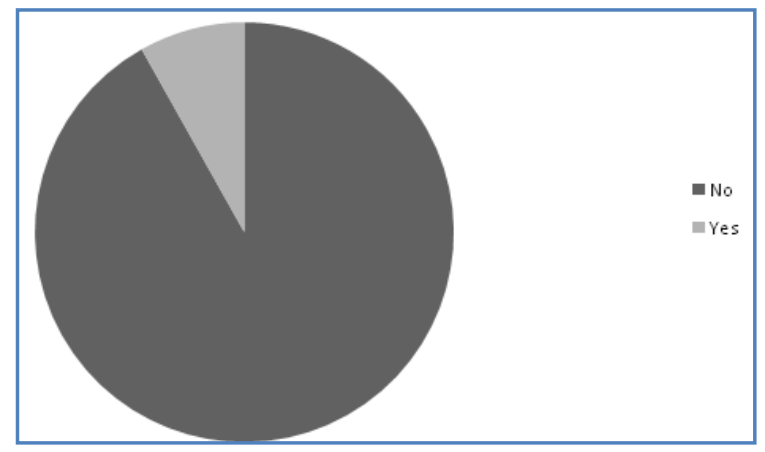

Fig. 5: Conduct their own Statistical Analysis 


\section{AUTHORS:}

1. Laxman Kumar

2. Kashif Shahnawaz

3. Sanjay Kr. Choudhary

4. Gautam Sarker

5. Sanjiv Kumar Barman

6. jitendra Bahadur Singh

\section{PARTICULARS OF CONTRIBUTORS:}

1. Assistant Professor, Department of Community Medicine, M.I.M.S. barabanki, Lucknow, Uttar Pradesh.

2. Assistant Professor, Department of Community Medicine, M.G.M. Medical College \& L.S.K. Hospital, Kishanganj, Bihar.

3. Senior Resident, Department of Community Medicine, I.G. M.S. Patna, Bihar.

4. Assistant Professor, Department of Community Medicine, M.G.M.M.C.H, Kishanganj, Bihar.
5. Post Graduate, Final yr, M.G.M.M.C.H, Kishanganj, Bihar.

6. Tutor, Department of Community Medicine, M.G.M.M.C.H,Kishanganj,Bihar.

\section{NAME ADDRESS EMAIL ID OF THE CORRESPONDING AUTHOR:}

Dr. Kashif Shahnawaz, Manhar Road, Chhoti Quazipura, Dist - Darbhanga, Bihar - 846004.

Email - kashif.shahnawaz98@gmail.com

Date of Submission: 20/12/2013.

Date of Peer Review: 21/12/2013.

Date of Acceptance: 09/01/2014.

Date of Publishing: 18/01/2014. 